\title{
EL EJERCICIO PROFESIONAL DEL TRABAJO SOCIAL CON ORGANIZACIONES DE DERECHOS HUMANOS: POSIBILIDADES, RETOS Y OPORTUNIDADES*
}

\author{
THE PROFESSIONAL EXERCISE OF SOCIAL WORK WITH HUMAN RIGHTS \\ ORGANIZATIONS: POSSIBILITIES, CHALLENGES AND OPPORTUNITIES
}

\section{Cristian Sebastián Castaño-Orozco**}

\section{Resumen}

Objetivo. Este artículo pretende ubicar una discusión entre los derechos humanos en relación con la coyuntura colombiana y el posible papel del trabajo social en relación con organizaciones defensoras de derechos humanos. Metodología. Se analizó la dinámica de los derechos humanos en el modo de producción capitalista, las tensiones consecuentes en el contexto colombiano entre dichas organizaciones con el Estado y otros actores, precisando especialmente en las lógicas que éstas presentan con el trabajo social. Resultado. Se identifica el carácter histórico y conflictivo de los derechos humanos, cómo este doble carácter se refleja en el escenario colombiano en episodios como el estado de sitio, la "guerra sucia” y la configuración del neoliberalismo. Conclusión. A pesar de la marginalidad del trabajo social, esta profesión cuenta con una oportunidad importante en términos de ampliar su quehacer profesional y los horizontes del proyecto profesional, anclado a la construcción de un proyecto éticopolítico profesional crítico.

Palabras clave: derechos humanos, trabajo social, contexto colombiano, política social, proyecto ético-político.

\begin{abstract}
Objective. This article aims to place a discussion between human rights in relation with the Colombian situation and the possible role of Social Work in relation to human rights defender organizations. Methodology. The dynamics of Human Rights in the capitalist mode of production are analyzed, as well as the consequent tensions in the Colombian context between these organizations with the State and other actors, especially in the logics they present with Social Work. Result. The historical and conflictive character of human rights is identified, how this double character is reflected in the Colombian scenario in episodes such as the state of siege, the "dirty war" and the configuration of neoliberalism. Conclusion. Despite the marginality of social work, this profession has an important opportunity in terms of expanding its professional work and the horizons of the professional project, anchored to the construction of a critical professional ethical-political project.

\footnotetext{
* Versión ampliada y con datos actualizados de la ponencia "Reflexión acerca de los retos y oportunidades para la práctica profesional de las y los trabajadores sociales con organizaciones de Derechos Humanos”, presentada al XV Congreso Colombiano de Trabajo Social, realizado en Neiva en el 2016. Constituye resultados parciales de los estudios de pregrado y especialización realizados entre 2016 y 2018 en la Universidad del Valle y la Fundación Universitaria Católica Lumen Gentium.

${ }^{* *}$ Fundación Universitaria Católica Lumen Gentium. Cali, Colombia. E-mail: chris.cast913@gmail.com.

(D) orcid.org/0000-0002-3011-1989 Google Scholar
} 
Key words: human rights, social work, colombian context, social politics, ethical-political project.

\section{Introducción}

Desde la profesión en su dimensión teórico-metodológica y ético-política, se ha vuelto un lugar común la necesidad de incorporar la perspectiva de derechos en el ejercicio profesional. Sin embargo, dicho imperativo, en numerosas ocasiones, se invoca de manera formal y acrítica, sin elevar discusiones como la concepción misma de los derechos humanos (DD. HH., en adelante), su caracterización, la relación entre los derechos a invocar por parte de la institución oferente de servicios profesionales con las necesidades, demandas y derechos de la población a intervenir, los efectos y consecuencias del ejercicio profesional en términos de la implementación de unos derechos carentes, en aras de un bienestar colectivo o una mayor precarización social en el contexto.

En otras palabras, existe la necesidad de ubicar la relación entre los DD. HH. con los diferentes contextos donde se ejerce la profesión, en especial cuando se trabajan en contextos donde se presentan conflictos sociales y, debido a ello, surgen -o se presentan desde fuera-organizaciones sociales que abogan por los derechos de las comunidades. En estos contextos, donde el ejercicio profesional del trabajo social se lleva a cabo con organizaciones no gubernamentales, instituciones del Estado, fundaciones y otras formas derivadas del Estado y el sector privado, pueden ocurrir diversas situaciones: por un lado, puede existir una consonancia entre los derechos exigidos por las comunidades y los que buscan abogar los oferentes de servicios profesionales, mientras que en otras situaciones no; lo cual conlleva a que el desarrollo de estrategias, programas y proyectos por parte del conjunto profesional en los territorios.

Sin embargo, en otros contextos esto no se presenta y, con ello, se profundiza el conflicto social y se precariza aún más a las comunidades y sus necesidades de reconocer, satisfacer y garantizar unos derechos carentes. De igual forma, este escenario puede conllevar cuestionamientos éticos acerca del ejercicio de la profesión y la relación entre la "identidad profesional" del/la trabajador/a social con la "perspectiva de derechos". La falta de dicha reflexión conlleva, entre otras cosas, a que el ejercicio profesional en determinados contextos, lejos de contribuir a la satisfacción de las necesidades sociales o la resolución de los conflictos sociales, puede conllevar a profundizar los daños y sufrimientos ya existentes en las personas.

El presente escrito, construido a partir de la reflexión que quien escribe ha logrado establecer en los últimos tres años entre el ejercicio del trabajo social en relación con los DD. HH. -en especial del ejercicio con las organizaciones de víctimas del conflicto sociopolítico 
armado y de DD. HH.- buscando con ello brindar aportes para ubicar posibles relaciones del trabajo social con los DD. HH., desde procesos de investigación y ejercicio profesional, con formas organizativas dedicada al reconocimiento y garantías de los DD. HH. De este modo, el presente escrito se compone de tres partes: en la primera, se pretende reflexionar sobre la caracterización e implementación de los DD. HH. en el marco de la sociedad capitalista. La segunda parte pretende relacionar la tensión entre la actual configuración del Estado colombiano, las organizaciones defensoras de DD. HH. y el ejercicio profesional del trabajo social. Por último, se ubican una serie de retos para potenciar dicho ejercicio, en clave de la construcción de un proyecto ético-político profesional crítico.

\section{Discusión}

\section{Derechos humanos y "perspectiva de derechos": una aproximación crítica}

Tras los estragos producidos por las naciones participantes en la Segunda Guerra Mundial, en vista de la necesidad de que un hecho de similares precedentes no volviera a ocurrir en la historia de la humanidad, se avizora la necesidad de establecer un marco normativo universal a todos los países del mundo. De ahí deviene la Declaración Universal de los Derechos Humanos de 1948, y con ello un conjunto de convenios y pactos internacionales que configuran el derecho internacional, acogido e implementado por los países dentro de sus normatividades internas. La pretendida "universalidad" de los DD. HH. queda reflejada en la presente cita, donde indica que las naciones:

\footnotetext{
Han reafirmado en la Carta su fe en los derechos fundamentales del hombre, en la dignidad y el valor de la persona humana y en la igualdad de derechos de hombres y mujeres, y se han declarado resueltos a promover el progreso social y a elevar el nivel de vida dentro de un concepto más amplio de la libertad. (Organización de las Naciones Unidas, ONU, 2015, p. 2)
}

Sin embargo, la añorada "universalidad” de los DD. HH. quedará en entredicho si se analiza su implementación mundial efectiva: las constantes violaciones que sufren las personas dada su ubicación en el sistema de clases sociales, el mapa geopolítico, su sexo, su género, su orientación social, su ideología política; se ve también cómo las ideas de "progreso social” y "desarrollo" arrasa con el medio ambiente, la cultura y el tejido social construido en los territorios que resisten ante aquellos “cantos de sirena”, y así mismo, las diferentes ideas de libertad propuesta por las sociedades deben rendir tributo a la suprema y (universal) libertad del mercado.

Por lo tanto, cabe la necesidad de revisar críticamente la caracterización y efectividad de los DD. HH., para luego ubicar reflexiones acerca de su finalidad última: la garantía del bienestar del 
conjunto de la población. Dicho esto, es necesario partir por entender los DD. HH. como una construcción histórica de los seres humanos, producto de su capacidad para pensar, proyectar una realidad, actuar sobre ella y reflexionar sobre sus consecuencias, una construcción alejada de toda idea de "naturalidad" y "determinismo" que permite comprender que tales derechos no son fijos y estáticos en el tiempo, pues cambian en la medida que las personas abogan por ellos y luchan por su otorgamiento y concreción efectiva. En ese sentido, se entiende que los DD. HH. no es algo que solo están ahí, sino que es algo deseado, por ende, es perseguido y en proceso de reconocimiento, motivo por el cual surgen disputas en términos de dichos objetivos en determinado contexto, tiempo y circunstancia.

Como los DD. HH. no están ahí sencillamente, no es posible hallar en ellos una fundamentación absoluta que justifique su existencia, por tanto, conceptualizarlos no es una tarea fácil (Bobbio, 2000), puesto que tiende a cometerse errores de orden tautológico, definiciones ideales sin contenido o una carga valorativa tal que permite su ideologización por parte del bloque de poder dominante, buscando con ello consolidar sus estructuras de dominación.

Así mismo, los DD. HH. son cambiantes de acuerdo con el tiempo histórico, el modelo de organización social, las necesidades, los intereses de clase, los medios disponibles para su realización y las transformaciones técnicas. De ahí que derechos como el derecho de propiedad, máximo custodio de la sociedad capitalista y su respectivo sistema jurídico-político, hoy en día son sumamente cuestionados, y derechos nunca antes mencionados hace dos siglos como los derechos sociales, resultan proclamados con gran ostentación en todas las declaraciones recientes. De ahí la necesidad de reconocer el entramado histórico, complejo y contradictorio de la realidad social para analizar las tensiones y conflictos en las disputas por el reconocimiento, efectividad y garantía de estos derechos.

Y es que en este punto es necesario ubicar a los DD. HH., no solamente desde su carácter histórico sino también desde su carácter conflictivo. Esto es la construcción de los DD. HH., su reconocimiento y ejercicio por parte de los grupos humanos, han girado a partir de enfrentamientos productos de diversos antagonismos. En ese sentido, cabe destacar que los primeros derechos reconocidos tienen que ver con la necesidad de las personas de otras religiones diferentes a la católica por practicar su culto en condiciones dignas, sin sufrir los castigos impuestos por el clero, lo cual precede a una discusión sobre las diferentes formas en que los seres humanos asumen la fe, encontrándose concepciones no solo diversas, sino también opuestas (Giraldo, 2010). Sin embargo, esta conquista de derechos surge en medio de la transición entre esclavismo y feudalismo, dos niveles de organización social donde conglomerados de seres humanos son reducidos al concepto de mercancía, la organización social se construye a partir de patrones de desigualdad y de una supuesta "naturalidad", castrando con ello al esclavo y al siervo de la gleba, la posibilidad de pensar en cuestiones como 
la libertad y el derecho universal, diferentes al "derecho natural" existente en aquel entonces (Trindade, 2013).

Ya en el proceso transitorio entre feudalismo y capitalismo se da un giro del "derecho natural” al "derecho positivo", protagonizado principalmente por los actores que irrumpen en la arena sociopolítica y determinarán la configuración del naciente orden social: la burguesía. Estos, al presenciar que el orden feudal y la configuración del "derecho natural” les impedía el libre desarrollo de la acumulación y circulación de capital, la libre contratación de fuerza de trabajo y la libre transformación en mercancía de todos los productos de trabajo, se vieron forzados a tomar las fuentes filosóficas del "derecho natural" y, en conjunto con los avances de la filosofía iluminista, se tornaron en sus armas para la transformación de la sociedad para el desarrollo de sus intereses.

De esta forma, la burguesía, con la colaboración fundamental del naciente proletariado industrial, logró conquistas que se vieron reflejadas no solamente en el derrocamiento de la monarquía y en la instauración de una nueva forma de gobernar, sino también en la generación de marcos normativos que pretendieran "garantizar" una gama de derechos a toda la población. En ese sentido, surgen cartas como la Declaración de Independencia de los Estados Unidos en 1776 y la Declaración de los Derechos del Hombre y del Ciudadano en 1789, esta última como conquista de la Revolución Francesa.

Sin embargo, autores como Coutinho (2010) señalan que, después de logradas sus conquistas, la burguesía abandona su senda progresista y se torna "una clase conservadora, interesada en la perpetuación y la justificación teórica de lo existente” (p. 22). Será en ese sentido cuando Marx (1967) lleva a cabo su crítica a la Declaración de los Derechos del Hombre, pues establece una crítica a la manera cómo el pensamiento social burgués configura los -nacientesDD. HH., en términos abstractos y formales, en forma de derechos eminentemente individuales. Así pues, Marx plantea que el marco de derechos construidos por los pensadores franceses establece la libertad religiosa, mas no la liberación del hombre de la religión, otorgan a los seres humanos la libertad de explotar, mas no la liberación de la propiedad privada sobre los medios de producción. Por ende, los derechos declarados en 1789, de acuerdo con Marx, no se construyeron basados a partir de la unión de los sujetos, sino en la libertad de su separación dentro de su comunidad, otorgándoles únicamente la emancipación política, mas no la posibilidad de romper las cadenas que les subyacen por medio de la emancipación humana.

De esta forma, en el desarrollo de la sociedad capitalista ocurrirán tres contradicciones relacionadas con los DD. HH. La primera aparece en el momento en que surgen nuevos derechos, logrados muchos de estos por las conquistas de las clases trabajadoras y con un debido reconocimiento por parte de los Estados, pero a la hora de justificar su existencia se 
encuentra incompatibilidades con otros derechos, razón por la cual en su aplicación algunos derechos se encargan de limitar o negar a otros, en especial cuando los bandos que reclaman para sí determinados derechos contrapuestos resultan siendo sectores de la sociedad o clases en conflicto o en evidente antagonismo, haciendo que tales derechos se contrapongan en un escenario de lucha de clases. En momentos como estos, surgen también antinomias relacionadas con la adquisición de libertades y poderes propios de estos derechos y ocurre que, de acuerdo con Bobbio (2000), la sumatoria de libertades implica la disminución de poderes y viceversa, lo cual genera conflictos a la hora de ubicar la primacía de unos derechos sobre otros.

Aun así, Bobbio (2000) concluye que el problema de fondo con los DD. HH. no tiene que ver con su justificación, sino con su protección efectiva, motivo por el cual los DD. HH. no se cierran en el terreno filosófico, es un tema eminentemente político. Tomando en cuenta esto, surge una segunda contradicción entre el formalismo abstracto contenido en la normatividad de los DD. HH. y su implementación efectiva en los territorios donde éste se exige, principalmente, por los sectores populares y clases trabajadoras. Frente a esto, Zuleta (2003) precisa que los DD. HH. no son suficientes con que existan, pues en el marco de un sistema democrático éstos deben acompañarse de posibilidades efectivas de realización. De esta forma, para Zuleta (2003):

\section{La existencia de unos derechos no es nada más que un mínimo, porque de nada sirven los derechos, como decía Marx, si no tenemos posibilidades: ¿de qué sirve que una persona, se pregunta, tenga derecho a elegir y ser elegido, si ni siquiera sabe leer? (p. 38)}

Concebir una definición crítica de los DD. HH. implica la necesidad de ir más allá de los postulados legalistas-formales que vacían el discurso sobre este tema. Implica recorrer el camino empleado por Marx de hallar la "contradicción fundamental entre los 'derechos del hombre' y la realidad de la sociedad capitalista, donde se cree que estos derechos estuvieran implementados" (Meszáros, 2008, p. 158).

Aun así, el avance importante en materia del reconocimiento y exigibilidad de los derechos conquistados por los sectores populares y las clases trabajadoras han hecho que los Estados, dentro de sus funciones de legitimación social, se reestructuren en su arquitectura y funcionamiento para primar su papel como garante de los derechos. En el caso de los países que se suman al reconocimiento de los pactos y convenciones promulgadas desde instancias como las Naciones Unidas y la Cruz Roja Internacional, entran a reconocerse como Estados Sociales de Derecho. De igual forma, la "perspectiva de derechos" obliga a los Estados a atender de forma inmediata y prioritaria a los sectores de la población que sufren una mayor marginación, exclusión y discriminación. Así mismo, con la emergencia de los "enfoques diferenciales", la "perspectiva de derechos" entra en diálogo permanente con otras perspectivas como la 
étnica, de género y de habilidades diversas, a fin de evitar toda forma de discriminación y daño al momento de implementar las políticas sociales. Dichas políticas, de acuerdo con esta perspectiva:

\begin{abstract}
Deben expresar el contenido específico de los servicios, prestaciones y protecciones sociales; la financiación para garantizar el acceso de quienes carecen de recursos; el aseguramiento de individuos, familias y grupos contra determinados riesgos; y la protección a quienes se encuentran en situaciones de vulnerabilidad específicas. (Rico de Alonso y Delgado como se citó en Delgado, 2002, p. 2)
\end{abstract}

No obstante, a la hora de abordar esta "perspectiva” en relación con los fines de todo Estado resulta inevitable hacer esta pregunta: si uno de los fines de todo Estado consiste en garantizar el bienestar social, como un paso para lograr el ideal simbólico de comunidad-nación, ¿por qué la necesidad de abordar la cuestión de los DD. HH. tan solo como una "perspectiva" y no como un fin misional de los Estados? El problema se agudiza al momento de evidenciar una tercera contradicción entre los postulados que soportan la existencia de un estado social de derecho con los resultados de las políticas sociales en impactar el bienestar de la población, las desigualdades y el goce efectivo de los derechos que el Estado dice garantizar. La respuesta a este cuestionamiento puede hallarse en el momento donde nace el concepto "perspectiva de derechos", de acuerdo con González (2013), este nace como necesidad por parte de las Naciones Unidas y sus organismos por posicionar un nuevo paradigma y criterio común en la cooperación del desarrollo, bajo la necesidad de anclar una relación que se refleja de igual forma en el concepto de "desarrollo humano". La cuestión es que ambos conceptos, “perspectivas de derechos" y “desarrollo humano", transitan por un callejón sin salida, pues ambos conceptos pasan de largo que el capitalismo, como sistema de relaciones sociales, produce en sí misma desigualdades, en sí mismo genera crisis y vive de ellas, puesto que ellas son esenciales para su misma reproducción "y en ellas sus desequilibrios son confrontados, remodelados y reorganizados para crear una nueva versión de su núcleo dinámico” (Harvey, 2014, p. 11).

Como se pretende apreciar a continuación, el desarrollo de los Derechos Humanos y la "perspectiva de derechos" en Colombia se encuentran atravesados por las configuraciones particulares del Estado y el régimen político colombiano, sus acciones en relación con los DD. HH. y las disputas de las organizaciones sociales que abogan por su defensa. Estos elementos determinan también el carácter de la política social existente sobre el tema y vislumbran el horizonte de acción profesional desde la profesión. 


\section{Derechos humanos, Estado y trabajo social en Colombia}

El Estado colombiano se ha caracterizado por pretender garantizar la concentración del poder sociopolítico y económico en un grupo social reducido que logre manejar sus hilos, en optar históricamente por un programa de control excesivo a los procesos de transformación social y ejercer una lógica de coerción/consenso hacia los procesos de corte progresistas y revolucionarios ${ }^{1}$. Frente a esto, Cueva (1983) asegura que la principal tarea de dicho Estado, bajo el control de un bloque de poder dominante conformado por sectores oligárquicosburgueses y terratenientes, es la de "forjar un marco jurídico-político adecuado a la acumulación originaria de capital, erigiéndose en una potencia supremamente autoritaria como para vencer toda resistencia que los grupos afectados pudiesen ofrecer" (Cueva, 1983, p. 134). La particularidad del caso colombiano se remite al nivel de autoritarismo logrado por los sectores dirigentes de los partidos liberal y conservador, quienes lograron enfrentar entre sí a sus bases populares, tal cual ocurrió en el Periodo de la Violencia (1948-1953), entrando en esa época a un periodo, casi permanente, de Estado de Sitio hasta el año 1991.

En términos de la defensa de los DD. HH., se puede decir que su historia se encuentra atada al entramado de las luchas sociales y de clases configuradas en el territorio colombiano, proceso que presenta como antecedentes importantes las rebeliones de esclavos, comuneros y sectores que exigían el reconocimiento de la Declaración de los Derechos del Hombre frente a un orden colonial con tendencias, no solo conservadoras, sino también reaccionarias hacia un nuevo "derecho natural" en el siglo XVIII (Aguilera y Vega, 1998); la avanzada libertadora protagonizada por Simón Bolívar, quien rebelde a la configuración de una "patria del criollo" aboga por la conquista de derechos y libertades universales a las poblaciones negras, indígenas y mestizas (Fernández-Retamar, 2006) y las luchas de las poblaciones artesanas en el siglo XIX; como también las luchas del naciente proletariado industrial y un grueso sector del campesinado reclamante de tierras despojadas por el capitalismo naciente en la primera mitad del siglo XX.

Sin embargo, para efectos de análisis, se tomará como punto de partida la década de 1970 a la hora de ubicar la defensa de los DD. HH. en Colombia, puesto que la radicalización de las protestas sociales, el avance de las organizaciones insurgentes en armas y el nivel de represión por parte de los gobiernos de turno, promovió la conformación de las primeras organizaciones de DD. HH. en el país: el Comité de Solidaridad con los Presos Políticos en 1972 y el Comité

\footnotetext{
${ }^{1}$ Muestra de dicha lógica consiste en el diálogo sostenido por el gobierno de Juan Manuel Santos (2010-2018) con las Fuerzas Armadas Revolucionarias de Colombia -Ejército del Pueblo FARC-EP-, agrupación insurgente que por más de 53 años ejerció una lucha armada contra el bloque de poder dominante y producto del cual surge un Acuerdo Final y que en este momento se encuentra en proceso de implementación. Dentro de los acuerdos alcanzados se encuentra la transformación del grupo guerrillero en partido político, hoy Fuerza Alternativa Revolucionaria del Común, la cual sostiene un ideario semejante al construido como insurgencia armada, pero ahora presente en el escenario político legal.
} 
Permanente por la Defensa de los Derechos Humanos en 1979. En este momento es posible evidenciar una primera tensión entre un Estado firmante de los pactos por los derechos civiles y políticos y de derechos económicos, sociales y culturales ${ }^{2}$, pero activo violador de los mismos bajo la justificación de actuar bajo los postulados del estado de sitio; y, por otra parte, se encuentra un grupo pequeño, pero activo, de organizaciones de DD. HH. que llevan a cabo diversas iniciativas destinadas a visibilizar las detenciones arbitrarias y las torturas como las modalidades principales de violaciones de derechos cometidas por las fuerzas del Estado. Esta tensión recoge elementos a favor de las organizaciones con la visita de Amnistía Internacional al país en 1980, el reconocimiento de la existencia de violaciones a los DD. HH. en Colombia y la obligatoriedad del Estado colombiano, en cabeza de Julio César Turbay Ayala, de llevar a cabo acciones tendientes a la protección de los derechos políticos y la derogación de las medidas coercitivas, como el estado de sitio y el Estatuto de Seguridad de 1978. A pesar de ello, para Bitar (2007), estas acciones no representan un compromiso real del Estado colombiano hacia el respeto de estos derechos, sino una respuesta estratégica frente a la posibilidad de perder apoyo económico y militar proveniente del exterior, mantener apoyo diplomático y gozar de una buena imagen ante la comunidad internacional ${ }^{3}$.

Una segunda tensión aparece en la década de 1980, cuando emergen diversos actores relacionados con configuraciones paramilitares provenientes de diversos rincones del país, en conjunto con grupos y carteles del narcotráfico, ambos con motivos diversos y combinados: el asesinato a líderes/sas sociales, comunitarios/as y defensores/as de DD. HH. y el establecimiento de control territorial en zonas propicias para el desarrollo de sus objetivos criminales. A la par de esto, el Estado colombiano atraviesa por una crisis de inoperancia real e incapacidad de cumplir con tareas como la administración de justicia, la satisfacción de las demandas sociales y la pérdida de control territorial. Es en este escenario donde a una parainstitucionalidad, definida por Palacio y Rojas (1990) como:

\begin{abstract}
Una serie de mecanismos de regulación social y resolución de conflictos que no recorren las vías más formales de corte constitucional o legal, sino que rigen por arreglos informales, por mecanismos ad hoc; ellos pueden ser legales o ilegales; son caminos alternativos a una institucionalidad rígida e incapaz de responder a los desafíos coyunturales del conflicto social o de la acumulación de capital. (p. 72)
\end{abstract}

En vista de que las fuerzas del Estado cuentan con la incapacidad de reprimir de forma física a las organizaciones defensoras de DD. HH., optan por la llamada guerra sucia, es decir, por

\footnotetext{
${ }^{2}$ Ambos pactos son aprobados por la legislación colombiana a través de la Ley 74 de 1968.

${ }^{3}$ Precisar, de igual manera, que este conjunto de hechos se lleva a cabo en un contexto latinoamericano sacudido por la presencia de las dictaduras en la mayoría de los países del Cono Sur en donde, de igual forma, se desconocían los DD. HH. de los opositores políticos a los regímenes dictatoriales y los valores como libertad e igualdad eran fuertemente condicionados a los mandatos militares.
} 
establecer alianzas con configuraciones paramilitares y carteles del narcotráfico para cumplir con la tarea que ellos, como forma-Estado, no pueden cumplir por las vías legales. En esa medida, se vislumbra un Estado colombiano que, en materia de derechos, opta por la combinación entre mecanismos formales-democráticos y la utilización de métodos altamente represivos, como el retorno a los estados de sitio durante la administración de Virgilio Barco, con un grave manto de impunidad hacia el hostigamiento al liderazgo social y la oposición política. Por su parte, las organizaciones defensoras de DD. HH. , dadas las circunstancias de los hechos, optan por el levantamiento de dos banderas: la defensa de la vida, la lucha contra la impunidad y la solución política al conflicto sociopolítico armado con las insurgencias presentes en aquel entonces. Así mismo, continúan ejerciendo una presión social hacia organizaciones de orden internacional en pro de visibilizar las violaciones que sufren debido a su ejercicio, ejercen una labor de sensibilización hacia la población nacional acerca de dichas violaciones y logran un mayor protagonismo en los territorios a partir del surgimiento de nuevas organizaciones, entre ellas la Asociación de Familiares de Personas Detenidas-Desaparecidas, ASFADDES. En esta ocasión, la tensión juega más a favor del Estado y las facciones de clase dominante que ven en dicha parainstitucionalidad una oportunidad para configurar y consolidar poderes territoriales de cara a afianzar la acumulación de capital.

Por su parte, la última tensión tiene que ver con la necesidad del Estado colombiano por instaurar un nuevo orden constitucional que se materializa en la Constitución Política de 1991. Si bien, en aquella el Estado pretende asumir una responsabilidad importante en materia de DD. HH. con el reconocimiento de una amplia gama de ellos que se recogen en los dos primeros títulos de la misma, en otros puntos el Estado permite abrir las compuertas que permitan el paso a una nueva forma de acumulación de capital caracterizado por una mayor flexibilidad en su mecanismo y una mayor depredación en las formas de reproducción capitalista, caracterizado entre otras por el aumento en la extracción de bienes comunes vía minería, agrocombustibles y proyectos de infraestructura.

De acuerdo con Estrada (2015), esta nueva forma de acumulación de capital, de fase neoliberal, ha conjugado la conformación de dos aspectos: uno, la constitucionalización sistemática de la naciente variante del modo de producción capitalista, y dos:

Las configuraciones y modalidades específicas de la guerra, que permiten establecer nexos entre el régimen de luchas, la destrucción de procesos organizativos populares, las dinámicas de expropiaciónapropiación territorial; y entre la economía de la guerra y los procesos de acumulación. (p. 264)

De esta forma, la consolidación en la prevalencia de los derechos del capital sobre los derechos de las comunidades por parte del bloque de poder dominante, han generado una serie de 
consecuencias que incentiva la dinámica de movilización social, no solamente por parte de las organizaciones de DD. HH., sino por todo el conjunto del movimiento social y popular: la flexibilización de las jornadas de trabajo, la ruptura del tejido social y comunitario por cuenta del despojo de tierras protagonizado por los actores armados y las empresas multinacionales, el daño al medio ambiente y los ecosistemas que configuran territorialidades opuestas al modelo de "desarrollo" capitalista, la imposición de usos de la tierra dirigido a la ganadería extensiva y la agroindustria, la precarización de los servicios sociales brindados por el Estado y el sector privado y la imposición de un modelo de crecimiento exponencial urbano a costa de la concentración de la pobreza y otros síntomas de la "cuestión social” propia de las periferias urbanas. Tanto los motivantes como las formas organizativas y las movilizaciones han configurado un aumento en la concientización social, proceso que se ha encaminado hacia la exigencia de reivindicaciones colectivas en el orden sociopolítico, económico y ambiental, que en últimas devienen en la exigencia de reconocer, satisfacer y garantizar, no solamente DD. HH., sino también derechos a la naturaleza y los seres que la componen. Debido a estas acciones, la agenda discursiva y de movilización sobre los DD. HH. - caracterización, reconocimiento, implementación, garantías, prevención y promoción- ha logrado posicionar la opinión pública, ubicando de igual forma la figura del defensor y la defensora de los DD. HH. como un actor fundamental para la construcción de una sociedad democrática donde primen la paz y la justicia social, en especial durante el actual proceso de transición política que se encuentra Colombia atravesando. Sin embargo, el posicionamiento y legitimidad que ha logrado conquistar las personas que representan los liderazgos sociales en los territorios ha implicado también que estas personas sean perseguidas con mayor saña por parte de diversos actores políticos, económicos y armados, mediante diversas formas cuyas tensiones mencionadas hacen parte de un andamiaje estratégico de orden contrainsurgente que pretende contener las dinámicas de movilización social que expresen descontento hacia el orden social existente, lo cual demuestra la incomodidad que la figura del defensor/defensora de DD. HH. representa para los intereses del bloque de poder dominante.

Aún así, dicho bloque representando mediante figuras como el Estado colombiano, adquiere las obligaciones de respetar y garantizar los DD. HH. de toda persona que se encuentre bajo su jurisdicción, sin discriminación alguna y de adecuar su institucionalidad hacia tales fines, y es en ese sentido que el accionar de las organizaciones de DD. HH., continúa a pesar de la persecución sistemática hacia su ejercicio que continúa en la actualidad. Sumado a ello, debido a las habilidades logradas en la experiencia, la capacidad de gestionar recursos con organismos internacionales y agencia de cooperación y la coordinación con instituciones de orden territorial y nacional, han permitido que en los últimos años -y a pesar del constante hostigamiento sufrido por las configuraciones paramilitares y el mismo Estado-, muchas organizaciones logran posicionarse en diversos escenarios a partir de acciones que contribuyen con la satisfacción del bienestar de las comunidades afectadas por el conflicto y, en general, por la vulneración a sus derechos, entre ellas labores de acompañamiento psicosocial, asistencia 
jurídica, promoción de empoderamiento comunitario, recuperación de tejido social y la reconstrucción de la memoria histórica.

Al llegar a este punto aparece un escenario paradójico con relación a nuestra profesión: a pesar de que en diversos conceptos sobre el trabajo social aparecen explícitos los DD. HH. ${ }^{4}$ como principio de trabajo, a pesar de las reflexiones acerca del origen y desarrollo del trabajo social en relación con ideales democráticos y humanitarios y que en el marco ético que soporta el ejercicio profesional en Colombia se aboga por la implementación de un "enfoque de derechos", a la hora de encontrar reflexiones acerca de la defensa de los DD. HH. en Colombia y de las organizaciones defensoras de DD. HH., como campo de acción, se encuentra un panorama poco explorado.

Con esto no se quiere decir que no existan profesionales vinculadas/os a organizaciones de DD. HH. Es más, es posible identificar dos lógicas de relacionamiento entre el ejercicio profesional del trabajo y las organizaciones defensoras de DD. HH.: una primera lógica tiene que ver con la implementación de proyectos comunitarios por parte de dichas organizaciones, sea de forma directa o mediadas por ONG, quienes logran la captación de recursos por parte de entidades del Estado o mediante agendas de cooperación internacional, y frente a lo cual, incurre en la búsqueda de profesionales capacitados hacia la ejecución de servicios sociales. Una segunda lógica de relacionamiento tiene que ver con la vinculación directa, mediante el ejercicio de la militancia sociopolítica, por parte de profesionales de trabajo social con las organizaciones de DD. HH.

Ambas lógicas presentan sus semejanzas y sus diferentes, sin embargo, es necesario explorar algunos motivos por los cuales dicho campo de acción sigue siendo poco atrayente, tanto en el ejercicio laboral como en la reflexión académica. Un motivo tiene que ver con las condiciones económicas de la mayoría de dichas organizaciones, lo que les impide el acceso a recursos suficientes para contar con un equipo de profesionales disponible para el cumplimiento de sus deberes, por lo que muchas veces el trabajo que las y los profesionales de trabajo social llevan a cabo dentro de ellas parte de la convicción y el compromiso desinteresado de sus integrantes con la labor que llevan a cabo, aunque eso también implica que la dedicación de tiempo no sea la propicia para un adecuado trabajo, lo cual es una característica propia de la vinculación profesional vía militancia sociopolítica, ante lo cual no importa el hecho de no devenir salario, existe un vínculo directo con un proyecto societario por parte del/la profesional que le impulsa a realizar la labor dentro de la organización.

\footnotetext{
${ }^{4}$ Un ejemplo de ello es la definición internacional del trabajo social de acuerdo con la Federación Internacional de Trabajadores Sociales: “ElTrabajo Social es una profesión y disciplina, dedicada y comprometida al desarrollo social, cohesión, y empoderamiento de los grupos vulnerables. Principios de justicia social, derechos humanos, responsabilidad colectiva, y respeto por la diversidad son aspectos centrales para el Trabajo Social”, cursivas propias.
} 
Otro motivo tiene que ver con la poca oferta que brindan estas organizaciones en el momento de promocionar prácticas pre-profesionales, obligatorias en el proceso de formación profesional, cuya apuesta para el surgimiento de reflexiones mediante trabajos de grado es sumamente importante para comprender su importancia en la reconstrucción del tejido social y para la misma profesión. En este punto se presenta una dificultad adicional y tiene que ver con la configuración de los tiempos de trabajo y la dinámica dentro de algunas de estas organizaciones, dado que ellas manejan su propio tiempo y, en el caso de organizaciones no consolidadas en el tiempo, con recursos materiales/económicos y proyectos en ejecución, muchas veces no convergen con los tiempos exigidos por las unidades académicas en términos de la dedicación de estudiantes en los centros de práctica, lo cual impide que muchas de estas organizaciones cuenten con las "competencias" exigidas por dichas unidades académicas para ofertar las prácticas, ante lo cual el gremio estudiantil opte por escoger entre las ofertas que cumplan con los parámetros establecidos, desconociendo la existencia de otras propuestas y posibilidades de acción desde la profesión, en otras miradas, otros contextos y otros grupos poblaciones que construyen y viven otras lógicas de vida.

Sin embargo, el principal motivo por el que este campo de acción es poco explorado en términos de la reflexión tiene que ver con el estigma que se tiene hacia el ejercicio de la defensa de los DD. HH., el liderazgo social y la oposición política al orden social existente, motivo por el cual quienes lo asumen terminan corriendo un alto riesgo por cuenta del constante hostigamiento que sufren por parte de diversos actores armados y sectores que integran el bloque de poder dominante. Tal como lo señala Romero (2010):

La estigmatización sufrida por los defensores de Derechos Humanos va desde afirmaciones como que son terroristas vestidos de civil, aparato subversivo no armado, estafetas de la guerrilla, idiotas útiles de la insurgencia, brazo político de la guerrilla hasta la invalidación o distorsión de su trabajo por el manejo estadístico de sus registros $(\ldots)$ La tendencia de estos sectores que ven con desconfianza la labor de las ONG's de Derechos Humanos es a calificarlos no como contradictores legítimos del gobierno sino como enemigos del Estado, desde un discurso descalificador y homogeneizador en el cual la defensa de los derechos humanos se asimila a complicidad con el "terrorismo", impidiendo diferenciar entre lo que es y lo que no es terrorismo, argumentando que el terrorista es un monstruo de la sociedad, al que no le asiste ningún derecho. (p. 162)

El accionar de las organizaciones de DD. HH. en Colombia resulta crucial en un contexto tan complejo como el colombiano, el cual permanece en enfrentamientos entre un Estado contra diferentes expresiones legales e ilegales que han declarado la guerra al orden social existente y propugnan por transformaciones sociales estructurales bajo la consigna de "combinar todas 
las formas de lucha posible”. Las propias dinámicas de estos enfrentamientos obligan a que actores sociales se involucren en la labor de visibilizar los impactos que se generan en éstos y propender por el respeto y la exigibilidad de los derechos de las víctimas que arrojan el accionar guerrerista, tanto de las fuerzas del Estado como de las fuerzas paramilitares e insurgentes. De ahí su importancia, debido a que ellas:

\begin{abstract}
Han jugado un papel importante en la consolidación de un espacio discursivo nacional y de política pública alrededor de estos derechos fundamentales que - desde su estatuto ético y político- regulan las prácticas de los actores involucrados en los distintos conflictos que afectan al país. (Sarmiento y Delgado, 2010, p. 79)
\end{abstract}

Si bien, muchas de las organizaciones defensoras de los DD. HH. hacen parte del movimiento social y popular colombiano y, como tal, aportan a la construcción de propuestas que buscan la superación del actual orden social capitalista, muchas veces deben enfocar su accionar hacia brindar garantías a la población que ha sido vulnerada en sus derechos, como por ejemplo acompañamiento jurídico y atención psicosocial. Producto de esta misión es que dichas organizaciones, a partir de su práctica, logran dar a conocer de manera directa el accionar represivo del Estado colombiano hacia el ejercicio de la organización y la protesta social, por lo cual establecen denuncias ante otras organizaciones y movimientos sociales, instituciones estatales y hacia la opinión pública en general, dichos atropellos. De ahí que quienes llevan a cabo esta labor corren un grave riesgo para su integridad, dado que con su accionar es posible que las víctimas del conflicto se pronuncien en el escenario político, contribuyen a su empoderamiento y adquieran conciencia de su situación, no solamente como víctima, sino también en su condición de sujetas y sujetos explotados por el modo de producción capitalista y los sectores oligárquicos, burgueses y terratenientes que le sostiene.

Un reciente informe, construido por diversas organizaciones de DD. HH. (AA. VV, 2018), dan cuenta de un panorama desolador para la defensa de los DD. HH.: entre el 1 de enero del 2016 y el 31 de julio del 2018 se registraron 343 asesinatos contra líderes y lideresas sociales en el país, 100 de estos cometidos tan solo entre el 1 de enero y el 31 de julio del 2018, cifra que supera la cantidad total de muertes ocurridas en 2016, que fue de 99 personas. Así mismo, el informe El Cambio del Programa Somos Defensores (2016) da cuenta que entre los años 1995 y 2015 fueron asesinados 729 defensoras y defensores de DD. HH., 346 de éstos durante los cinco primeros años del gobierno de Juan Manuel Santos, contando en el 2015 con 682 agresiones, 539 amenazas, 63 asesinatos, 35 atentados, 26 detenciones arbitrarias y 3 desapariciones. Cifras que contrastan con la tasa de homicidios en aquel año cuando bajó de 13.343 casos en el 2014 a 12.673, mientras que el accionar de la insurgencia de las FARC-EP -en aquel momento en proceso de diálogos con el gobierno nacional- se redujo en un 94\%, 
los enfrentamientos FARC- EP-Ejército reducidos en un $72 \%$ y la muerte de civiles en el marco del conflicto en un $98 \%$.

Debido a esto, la firma del Acuerdo Final de Paz entre las FARC-EP y el gobierno nacional en noviembre del 2016 otorga una oportunidad importante en términos de políticas sociales y acciones emprendidas por la comunidad internacional, especialmente en los territorios más afectados por la dinámica de la guerra, y con ello una oportunidad por parte del trabajo social en contribuir a la construcción de una paz estable y duradera. Sin embargo, la propia implementación del Acuerdo Final de Paz es, hoy en día, un campo de disputa entre el Estado colombiano, la Fuerza Alternativa Revolucionaria del Común y las organizaciones sociales presentes en los territorios, debido a las diversas visiones que se tienen sobre el proceso: mientras que por un lado las organizaciones ven en la implementación de este acuerdo la oportunidad de satisfacer las demandas sociales y las carencias materiales que sufren por cuenta del abandono estatal en sus territorios, por parte del Estado -y en especial del bloque de poder dominante que se representa en él- la implementación es la oportunidad para que la institucionalidad y el sector privado pueda llegar sin dificultades a los territorios, en especial para el desarrollo de proyectos minero-energéticos y de infraestructura, en combinación con una política social servil a los intereses de dicho bloque de poder. De acuerdo con Montaño (2004):

Como solución parcial de la crisis capitalista, el neoliberalismo pretende la reconstitución del mercado, reduciendo e incluso eliminando la intervención social del Estado en diversas áreas y actividades. Así, en esa nueva estrategia hegemónica (neoliberal) del gran capital, se concibe un nuevo trato a la "cuestión social". Se crea una modalidad polimórfica de respuestas a las necesidades individuales, diferente según el poder adquisitivo de cada quien. Por tanto, tales respuestas no constituirían derecho, sino una actividad filantrópico/voluntaria o un servicio comercializable; también la calidad de los servicios responde al poder de compra de la persona, la universalización cede lugar a la focalización y descentralización, la solidaridad social pasa a ser localizada, puntual, identificada a la auto-ayuda y a la ayuda mutua. (p. 3)

De esta forma, las políticas sociales transitan por una contradicción entre legitimar los intereses de clase del bloque de poder dominante y suplir las necesidades de los sectores sociales beneficiados con su accionar. De esta forma, el accionar de dichas políticas se caracterizan por su focalización, es decir, por su dirección hacia atender problemáticas bastante urgentes a las poblaciones, a partir de soluciones de corte asistencialista y cortoplacista que otorgan soluciones paliativas que volverán a aparecer en un corto tiempo. A su vez, las responsabilidades no serán de exclusiva responsabilidad del Estado, sino que dichas políticas sociales serán privatizadas y entregas a organizaciones del sector privado, principalmente fundaciones. 
Esta situación conlleva a consecuencias en el ejercicio profesional como, por ejemplo, la prestación de servicios focalizados, precarizados y, para el caso de quienes invocan la "perspectiva de derechos" en su accionar, estos quedan reducidos a la eficacia económica que se puede sustraer a futuro (Gargarella, 2006).

\section{Oportunidades y retos desde el trabajo social al ejercicio profesional con organizaciones de Derechos Humanos}

Al llegar a este punto es posible afirmar que, a pesar de los riesgos e implicaciones que tiene el ejercicio profesional con organizaciones defensoras de DD. HH., se tiene también una oportunidad para que trabajadores sociales extiendan su quehacer profesional, bien sea desde la formación profesional, la investigación y el ejercicio profesional con víctimas del conflicto armado y demás personas a las que se les violentan sus derechos. En este sentido, ampliar los marcos referentes al quehacer profesional en Colombia, contribuye de igual forma a ampliar los horizontes del proyecto profesional del trabajo social, vinculado a su vez a un proyecto societario donde se establezcan reflexiones acerca de las relaciones sociales y la incorporación de demandas y aspiraciones cambiantes de acuerdo con las coyunturas históricas y políticas, siempre y cuando estas sean a favor de los intereses de las clases trabajadoras (Netto, 2003).

Ahora bien, de acuerdo con Schön (1983), este tipo de escenarios crean escepticismos en cuanto a la efectividad de las y los trabajadores sociales a la hora de manejar las herramientas teórico-metodológicas y ético-políticas de la profesión, sea por la sobre-estimación de las funciones que estos llevarían a cabo, porque sus acciones han sido insuficientes a la hora de contrarrestar determinadas problemáticas o, al contrario, han conllevado a empeorar las problemáticas iniciales; lo que conduce a una crisis de confianza, no porque se dude de la efectividad de dicha acción en el contexto, sino por las expectativas en cuanto los resultados de dicha acción.

En efecto, esta situación de riesgo que deben enfrentar las y los profesionales que, a su vez, sean defensores/as de DD. HH. en su trabajo cotidiano "ha provocado un freno en sus actuaciones, restricciones en sus labores, cierto ensimismamiento y autocensura, por el miedo a ser blanco de ataques" (Romero, 2010, p. 163). Esto hace parte del abanico contextual "complejo y cargados de incertidumbres” (Schön, 1983), lo que nos invita a plantear de antemano retos a la hora de leer estos contextos y, a partir de estas lecturas, poder llevar a cabo planes y métodos acordes con las necesidades de las personas con quienes se trabaja.

Entonces, si nuestra acción profesional debe ser una acción consciente y con un carácter permanentemente reflexivo, resulta imperativo tener en cuenta el contexto en el cual se ejerce nuestro accionar, lo que conduce a la necesidad de analizar de manera crítica la realidad social en donde se insertan las y los profesionales. De ahí que el primer reto que 
permita una relación entre el ejercicio profesional en trabajo social con las organizaciones de DD. HH. sea el reconocer y profundizar el análisis relacionados con las condiciones estructurales y coyunturales que configuran la historia de nuestro país, como por ejemplo reconocer los hechos tras el desarrollo y dinámicas del conflicto armado en Colombia, reconociendo en este fenómeno sus raíces sociales, económicas y políticas, sus actores, intereses e impactos que dejan las relaciones sociales existentes entre el Estado, los grupos armados, las comunidades y el conjunto de la sociedad civil.

De igual manera, analizar las condiciones estructurales y coyunturales ligadas a la conflictividad histórica en nuestro país implica en ubicar la actualidad ligada a los conflictos sociales sucedáneos a la construcción de paz en el marco de las particularidades propias de la lucha de clases, en especial los relacionados con los avances y las dificultades de la implementación del Acuerdo Final de Paz en los territorios rurales y urbanos. Producto de este accionar es, por ejemplo, el logro alcanzado por las organizaciones sociales en que se reconozca, por parte del Estado colombiano y la comunidad internacional, la existencia de un conflicto armado interno, el reconocimiento de violaciones a los DD. HH. por parte del Estado y la existencia de prisioneros/as políticos/as que, aún con la firma del Acuerdo Final de Paz y la promulgación de una ley de amnistía, se encuentran pagando condenas en las cárceles colombianas por el sencillo hecho de pensar de manera diferente al pensamiento hegemónico impuesto por las clases dominantes en el país.

Ser trabajador/a social y a la vez defensor/a de DD. HH. pasa por el ejercicio de cuestionar la información brindada por los medios de comunicación oficiales, elaboradas como supuestas "versiones oficiales" de la historia nacional. Se trata, por ende, de analizar y realizar la labor en beneficio de los sectores populares en labores de acompañamiento hacia las propuestas e iniciativas que surgen dentro de ellos, e inclusive mediar en la existencia de conflictos en dichas comunidades u organizaciones, como también el apoyo desde nuestro quehacer profesional a la,

\footnotetext{
dinamización de procesos tendientes al reconocimiento dialógico de las condiciones socio-históricas en las que se configuró la victimización, y la reconstrucción de identidades (individuales y colectivas) en tomo a la realización y potenciación de recursos propios y la exigencia de derechos. (Dueñas y Vélez, 2014, p. 375)
}

Esta situación nos lleva a reflexionar acerca del componente ético-político y sobre la concepción de derechos en el ejercicio profesional de las y los trabajadores sociales, y esto es importante en la medida que: 
La política que orienta la intervención social se fundamenta a partir de la mirada ética y de derechos, la cual establece los parámetros para leer y analizar la realidad, así como para formular y realizar los procesos de intervención, conducentes a transformar y mejorar las condiciones y calidad de vida de la sociedad. (Arias, 2007, p. 26)

Sin embargo, la mirada ética y de derechos se encuentra hegemónicamente plasmada bajo aquel principio del liberalismo político que nos recuerda Zizek (2004), eres libre de tomar cualquier decisión, siempre y cuando sea la decisión correcta. Aquello implica la existencia de una visión de la ética y de los DD. HH., hegemónicas, que se plasman en la práctica de la intervención social de las diferentes profesiones que tratan con las personas. Desconocer este hecho implica cerrar los ojos ante la realidad existente, por lo que el segundo reto gira en torno a analizar críticamente los discursos y prácticas relacionadas con las dimensiones éticopolíticas y los DD. HH. en las diferentes instituciones en donde profesionales de trabajo social ejercen su labor, dejando en claro la posible -y necesaria- sintonía del proyecto profesional con un proyecto de sociedad acorde a las necesidades de las clases trabajadoras y de los sectores populares.

Para ello es necesario también identificar las particularidades propias de los territorios y las poblaciones con las que el/la profesional se relaciona. Al tomar el caso concreto de la ciudad de Cali, se encuentra demográficamente compuesta por población afrodescendiente y aparte de eso es una ciudad históricamente receptora de población desplazada forzadamente, a raíz del conflicto armado, ante lo cual encuentran en esta ciudad un lugar en donde pueden reconstruir sus vidas. Dicha situación impone un tercer reto consistente en reconocer las particularidades de cada una de las personas en lo referente a lo étnico, género, clase social y grupo etario, más allá de los llamados "enfoques diferenciales". El contexto colombiano es profundamente diverso, por lo cual este reto implica afinar las habilidades para reconocer cada una de las particularidades que se encontrarán en nuestros procesos de ejercicio profesional con cada una de estas poblaciones, reconociendo la existencia de otro/otra que cuenta con historias, significados, representaciones, imaginarios y derechos que deben tenerse en cuenta a la hora de construir el vínculo profesional -y si se puede afectivo- con ese otro/otra. Eso sí, aclarando que abordar las particularidades de los contextos y los sujetos no impliquen ser separados de las condiciones estructurales y coyunturales que, para el caso de la realidad social, requiere una perspectiva de totalidad que, en sí misma, resulta dinámica y dialéctica puesto que los hechos supuestamente aislados son reconocidos por el movimiento mismo de la realidad y los sujetos que la componen.

Sin embargo, y esto advierte Montaño (2004), la política social ha tenido una relación con el trabajo social, bien sea de instrumentalidad profesional o de base de sustentación laboral de la profesión. En ambas relaciones se afectan de diversas formas la labor de trabajadores sociales 
en este ámbito, lo que conlleve a una crisis en el patrón de práctica profesional, repercutiendo en su condición de trabajador/a, en la demanda de profesionales y en su práctica de campo.

Estos elementos, señala el autor, nos conduce a la necesidad de contribuir a la construcción de un proyecto ético-político crítico por medio de la construcción de un proyecto profesional contrahegemónico en donde las posturas éticas parten de reflexiones eminentemente políticas y donde lo político sea el escenario donde se concretiza la ética de los sujetos. Hacia el sentido propuesto por Montaño se dirige el cuarto reto, reconociendo en igual medida que el proyecto ético-político profesional debe insertarse en el marco de un proyecto societario que parta de elementos como la construcción de ciudadanías críticas y su capacidad de autodeterminación, la democracia, los DD. HH. y la justicia social. En Colombia esta construcción es incipiente, entre otras razones por la persecución política a toda forma de oposición política al orden social existente y por la débil organización del gremio profesional, lo que reduce la posibilidad de que se gesten espacios de reflexión y debate permanente en lo que se refiere a este tema. Sin embargo, más que un hecho a lamentar, es un reto y una oportunidad más para enfrentar como gremio profesional. Tal como lo afirma Sierra (2014):

\begin{abstract}
Asumir la construcción de un proyecto ético-político profesional es una oportunidad para robustecer y renovar (y/o de superar) estas formas de organización profesional-institucional, con base en las reflexiones y acumulados que se construyan colectivamente en una convocatoria de participación amplia y plural, que no será fácil que sea efectiva dada la histórica baja participación que se ha promovido. (p. 2)
\end{abstract}

Dichas reflexiones y acumulados no serán posibles si no se reconocen las habilidades y los límites de nuestra acción profesional, así como las tensiones y contradicciones que atraviesa nuestra profesión, no solamente en nuestros espacios laborales sino también afuera de ellos. Por ello, "la construcción de dicho proyecto no será posible sin una reflexión conjunta sobre la interpretación que tenemos de la realidad social colombiana, asumiendo que ésta es, en buena parte, determinante de nuestro ser y hacer profesional" (Sierra, 2014, p. 3), lo cual implica que la construcción de dicho proyecto pasa por superar actitudes pasivas o conformistas que tienen que ver con la aceptación de una realidad social impuesta desde el exterior como "natural" e "inevitable" reconociendo, en cambio, a la realidad social como movimiento permanente donde las personas actúan de acuerdo con las circunstancias, en permanente conflictividad y antagonismo.

En todos los campos en donde el trabajo social ejerce su práctica profesional, se manifiestan tales conflictividades y antagonismos, a lo que todo profesional cuenta con dos opciones: o contribuir a la reproducción del orden social existente - lo que en el caso de trabajar con organizaciones por la defensa de los DD. HH. significa mantener una relación pasiva con el 
Estado o con actores privados dirigidos a la concertación, aprobación, implementación y aplicación de políticas o programas encaminadas a atender situaciones paliativas que, en ningún momento, satisfacen las necesidades de la población víctima de violaciones a sus derechos-, o bien sea contribuir al desarrollo de proyectos alternativos al servicio de los sectores y clases sociales oprimidas, como el caso de promover formas organizativas que, teniendo en cuenta las necesidades y demandas de la población víctima de las violaciones a sus derechos, encaminen sus objetivos hacia la satisfacción de tales necesidades y demandas, partiendo de una relación con el Estado o con el sector privado que no parta de la sumisión hacia los mandatos y requerimientos de los últimos. Dicha capacidad de elegir es la esencia ética de las y los profesionales cuya reflexión acerca de su papel profesional ocupa "una dimensión eminentemente política, estando en juego el sentido social de la actividad de este agente" (Iamamoto como se citó en Barroco, 2004, p. 191), entendiendo a su vez que la construcción del proyecto ético-político profesional crítico no se pretende imponer a partir de realidades estáticas e inmutables, por el contrario, dicha construcción debe ser entendida desde el ámbito de la posibilidad y de lo histórico, con sus lógicas de constante movimiento y cambio de acuerdo con las relaciones sociales humanas y de producción en el contexto colombiano y latinoamericano.

\section{Conclusiones}

Lejos de una pretendida visión de unversalidad y armonía respecto a los DD. HH., se evidencia cómo dicha categoría, a la hora de ser puesta en cuestión con su implementación efectiva en los territorios, se entrecruza con un doble carácter: por un lado, un carácter histórico, en el cual determinados derechos surgen en el marco de tiempos, circunstancias, relaciones sociales, configuraciones de ordenes e intereses contrapuestos entre sectores de la sociedad que se enfrentan por una serie de demandas. De ahí deviene su segundo carácter, el conflictivo, en el cual se evidencia como la conquista de los derechos, principalmente por parte de los sectores populares y clases trabajadoras, se han logrado producto de las luchas sociales y de clases.

En ese sentido, el cuestionamiento tiene que ver con la existencia, carácter e implementación de los DD. HH. en el marco de la sociedad capitalista, de la cual surgen tres contradicciones: la primera, tiene que ver con la incompatibilidad entre derechos en determinados momentos históricos, en especial cuando ambos derechos son invocados por sectores en antagonismo, y por ende, se invocan en un escenario de lucha de clases. La segunda contradicción tiene que ver con el carácter formal-abstracto que presentan los DD. HH. en contraposición con su implementación de acuerdo con los marcos del modo de producción capitalista, un sistema que, en sí mismo, genera desigualdades, lo cual obstruye la finalidad máxima de los DD. HH., como es el logro del bienestar social y la dignidad humana. Por su parte, la tercera contradicción tiene que ver con los principios del Estado Social de Derecho y su invocación permanente a la "perspectiva de derechos", en contraposición con el carácter precarizado de las políticas sociales ejecutadas por el mismo Estado y por el sector privado a través de formas 
organizativas como las fundaciones, asociaciones, las ONG, entre otras, las cuales se tornan reproductoras de las desigualdades inherentes al capitalismo.

En ese sentido, surge una serie de tensiones entre la configuración del Estado en el modo de producción capitalista con los DD. HH. Para el caso colombiano, dichas tensiones se evidencian a partir de la década del setenta cuando el aumento de la radicalidad producto de las movilizaciones sociales protagonizadas por las insurgencias armadas y no armadas representadas en partidos, sindicatos y otras formas asociativas, generan que el Estado responda con violencia y represión hacia dichos grupos frente a las demandas de orden laboral, rural y de prestaciones sociales. En este escenario es donde surgen las primeras organizaciones de DD. HH. en Colombia, quienes inician una lucha frontal por el derecho a la oposición política, el respeto a la vida y a las libertades democráticas.

Con las primeras conquistas de estas organizaciones, la tensión inicial se transforma: los principales actores represivos dejan de ser abiertamente el Estado para luego ser las configuraciones paramilitares, quienes logran configurar una parainstitucionalidad en la cual el control social y la resolución de conflictos se rigen más allá de la normatividad constitucional y la legalidad, frente a las limitaciones propias del Estado y el monopolio del uso de la fuerza. Con el pasar del tiempo, y con la conquista de más derechos por parte de las organizaciones sociales, se asiste a una tercera tensión, relacionada con la consolidación de un modelo económico de orden neoliberal que contribuye fortalecer los mecanismos jurídicos en defensa de los "derechos del capital" sobre los derechos de las comunidades rurales y urbanas, a partir de políticas económicas dirigidas al despojo de territorios en aras del desarrollo de proyectos minero-energéticos y agroindustriales, en conjunto con el crecimiento exponencial de la población urbana y la generación de proyectos que precarizan aún más las poblaciones.

En este escenario, se reflexiona sobre el accionar marginal de la profesión y su presencia a partir de dos lógicas de relacionamiento con organizaciones de DD. HH.: mediante la prestación de servicios sociales a cambio de un salario y el relacionamiento por medio de la militancia sociopolítica de las y los profesionales, quienes actúan en dichas organizaciones de manera desinteresada y en consonancia con un proyecto societario alternativo al existente. Sin embargo, la marginalidad entre el gremio profesional y las organizaciones de DD. HH. puede explicarse por tres factores: la falta de condiciones económicas de las organizaciones de DD. HH. para la contratación de personal profesional, la poca oferta que éstas logran ubicar en los escenarios de prácticas preprofesionales y el riesgo que implica hoy por hoy en Colombia ser defensor/ra de los DD. HH., dada la dinámica de la estrategia contrainsurgente.

A pesar de esto, existe una oportunidad importante por parte del trabajo social en su relación con las organizaciones de DD. HH., no solamente en términos del ejercicio profesional, sino también en las reflexiones propias de la formación y la investigación social. De esta forma, las 
oportunidades se encaminan hacia la extensión del quehacer profesional y, así mismo, hacia la ampliación de los horizontes del proyecto profesional del trabajo social en Colombia en relación con la construcción de un proyecto societario donde profesionales se comprometan con la defensa de los intereses de los sectores populares y las clases trabajadoras.

De igual forma, se ubican cuatro retos en la relación entre trabajo social y las organizaciones de DD. HH.: el primero tiene que ver con el reconocimiento y la profundización del análisis estructural y coyuntural de la historia del país, asociada a una trama conflictiva enmarcada en las particularidades propias de la lucha de clases en los territorios. Un segundo reto tiene que ver con el análisis crítico que las y los profesionales debemos hacer frente a los discursos y prácticas relacionadas con las dimensiones ético-políticas y los DD. HH. en los diferentes lugares donde el gremio profesional ofrece sus servicios sociales. Un tercer reto se dirige hacia el reconocimiento de las particularidades propias de los contextos y las poblaciones con quienes se trabaja, enmarcando dichas particularidades dentro de una perspectiva de totalidad, es decir, dentro de la realidad en movimiento. Por último, dicha relación contribuye a que el gremio profesional aporte a la construcción de un proyecto ético-político profesional crítico a partir de la construcción de un proyecto profesional contrahegemónico cuyas bases se enmarquen en el despertar de ciudadanías críticas, la defensa de la democracia y los DD. HH., como también la construcción paulatina de una paz con justicia social.

\section{Referencias}

AA.VV. (2018). ¿Cuáles son los patrones? Asesinatos de Líderes Sociales en el Post Acuerdo. Recuperado de http: / /iepri.unal.edu.co/fileadmin/user_upload/iepri_content/boletin/patrones6.pdf.

Aguilera, M. y Vega, R. (1998). Ideal democrático y revuelta popular. Bogotá, Colombia: CEREC, IEPRI \& Universidad Nacional de Colombia.

Arias, R. (2007). Aportes de una lectura en relación con la ética del cuidado y los derechos humanos para la intervención social en el siglo XXI. Revista Trabajo Social, 9, 25-36.

Barroco, M. (2004). Ética y servicio social: Fundamentos ontológicos. São Paulo, Brasil: Cortez Editora.

Bitar, S. (2007). Los primeros pasos de los Derechos Humanos en Colombia: La adaptación estratégica en el gobierno de Julio César Turbay. Bogotá, Colombia: Ediciones Uniandes.

Bobbio, N. (2000). El fundamento de los derechos humanos. En R. Soriano., C. Alarcón. y J. Mora. (Eds), Diccionario crítico de los Derechos Humanos (pp. 9-16). Andalucía, España: Universidad Internacional de Andalucía.

Coutinho, C. N. (2010). O estruturalismo e a miséria da razão. São Paulo, Brasil: Expressão Popular. 
Cueva, A. (1983). El desarrollo del capitalismo en América Latina. Ciudad de México, México: Editorial Siglo XXI.

Delgado, A. (2002) Las políticas sociales en la perspectiva de los derechos y la justicia. Recuperado de https: / /www.cepal.org/mujer/noticias/noticias/1/11151/delgado.pdf.

Dueñas, T. y Vélez, G. (2014). Trabajo social y pedagogía de la memoria desde los derechos humanos. Revista Prospectiva, 19, 359-386.

Estrada, J. (2015). Acumulación capitalista, dominación de clase y rebelión armada. Elementos para una interpretación histórica del conflicto social y armado. En AA.VV. (Eds), Conflicto social y rebelión armada en Colombia: Ensayos críticos (pp. 253-318). Bogotá, Colombia: Editorial Gentes del Común.

Fernández-Retamar, R. (2006). Pensamiento de Nuestra América. Buenos Aires, Argentina: Consejo Latinoamericano de Ciencias Sociales, CLACSO.

Gargarella, R. (2006). Carta abierta sobre la intolerancia: apuntes sobre derecho y protesta. Buenos Aires, Argentina: Editorial Siglo XXI.

Giraldo, J. (2010). Derechos Humanos y cristianismo. Trasfondo de un conflicto. Bogotá, Colombia: Editorial El Búho.

González, H. (2013). ¿Por qué políticas públicas sectoriales con enfoque de Derechos Humanos para Colombia? Razones para pensar y actuar sobre la pobreza y la desigualdad con intervención social para la democracia y la ciudadanía. En AA.VV. (Ed), La acción social en los Derechos Humanos (pp. 193-240). Bogotá, Colombia: Ediciones Anthropos Ltda.

Harvey, D. (2014). Diecisiete contradicciones y el fin del capitalismo. Quito, Ecuador: Editorial IAEN.

Marx, K. (1967). La sagrada familia y otros escritos filosóficos de la primera época. México D.F., México: Editorial Grijalbo.

Mészáros, I. (2008). Filosofia, ideologia e ciência social. São Paulo, Brasil: Editorial Boitempo.

Montaño, C. (2004). Hacia la construcción del proyecto ético-político profesional crítico. Recuperado de http://www.ts.ucr.ac.cr/binarios/congresos/reg/slets/slets-018-045.pdf.

Netto, J.P. (2003). La construcción del proyecto ético-político del Servicio Social frente a la crisis contemporánea. En E. Borgianni., Y. Guerra. y C. Montaño. (Orgs.), Servicio Social Crítico, hacia la construcción del nuevo proyecto ético-político profesional (pp. 271-296). São Paulo, Brasil: Cortez Editora.

Organización de las Naciones Unidas, ONU. (2015). Declaración Universal de los Derechos Humanos. Recuperado de https://www.un.org/es/documents/udhr/UDHR_booklet_ SP_web.pdf. 
Palacio, G. y Rojas, F. (1990). Empresarios de la cocaína, parainstitucionalidad y flexibilidad del régimen político colombiano: narcotráfico y contrainsurgencia. En G. Palacio. (Comp.), La irrupción del Paraestado: ensayos sobre la crisis colombiana (pp. 69-104). Bogotá, Colombia: ILSA-CEREC.

Programa Somos Defensores. (2016). El cambio: Informe anual SIADDHH 2015 sobre agresiones contra Defensores de Derechos Humanos en Colombia. Recuperado de https: / / somosdefensores. org/wp-content/uploads/2018/08/Documentos/TODOS\%20LOS\%20INFORMES/

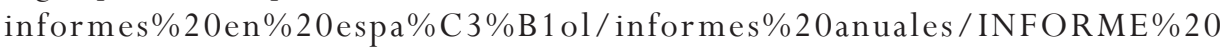
SOMOS\%20DEFENSORES\%202015\%20ANUAL_ESPA\%C3\%91OL.pdf.

Romero, F. (2010). La defensa de los Derechos Humanos. Organizaciones y redes en Colombia. En AA.VV. (Eds), Defender y proteger la vida: La acción de los defensores de Derechos Humanos en Colombia (pp. 151-169). Bogotá, Colombia: Programa Somos Defensores.

Sarmiento, F. y Delgado, J. (2010). Derechos humanos y movilización por la paz en Colombia: Motivos, repertorios, actores y dinámicas recientes. En AA.VV. (Ed), Defender y proteger la vida: La acción de los defensores de Derechos Humanos en Colombia (pp. 79-97). Bogotá, Colombia: Programa somos Defensores.

Schön, D. (1983). El profesional reflexivo. Cómo piensan los profesionales cuando actúan. Barcelona, España: Editorial Paidós.

Sierra, J.P. (2014). Una propuesta de construcción de un proyecto ético-político profesional del Trabajo Social en Colombia. Bogotá, Colombia: Mimeo.

Trindade, J. (2013). Os direitos humanos: para além do capital. En V. Forti. \& C. Brittes. (Orgs.), Direitos Humanos e Serviço Social: Polêmicas, debates e embates (pp. 11-28). Rio De Janeiro, Brasil: Editora Lumen Juris.

Zizek, S. (2004). Repetir Lenin:Trece tentativas sobre Lenin. Madrid, España: Akal Ediciones.

Zuleta, E. (2003). Colombia: violencia, democracia y derechos humanos. Bogotá, España: Ediciones Hombre Nuevo. 